\section{Avian selection}

\section{Tim Halliday}

Naturalized Birds of the World. By Sir Christopher Lever. Illustrations by Robert Gillmor. Longman, Harlow, $U K /$ Wiley, New York: 1987. Pp.615. £65, \$197. Extinct Birds. By Errol Fuller. VikingRainbird, London/Facts on File, New York: 1987. Pp.256. £20, \$35.

THE impact of human civilization on the world's avifauna has been mixed. The great majority of species have declined in numbers, primarily as the result of habitat destruction, and there has been a dramatic increase over the past 300 years in the rate at which birds have become extinct. A few species, however, have prospered as a result of human activities and have been able to establish breeding populations in parts of the world where they did not previously exist.

Such 'naturalized' species are the subject of Christopher Lever's authoritative book. Lever's aim was to document, for every naturalized species in the world, exactly where, when and how it has established new breeding populations, and to assess the effect such populations have had on the existing biota. The mass of detailed information that Lever has compiled is clearly and systematically laid out, with separate world maps for each species to show its original range and the location of its naturalized populations, and an excellent line drawing by Robert Gillmor. Each entry also contains separate accounts for each new locality where a species has become established.

As described in Lever's introduction, birds have found their way to new parts of the world for a variety of reasons. Many were deliberately taken by colonists to provide food or sport, and some, notably songbirds, were taken simply to provide fond memories of home. More recently, birds have been transported for scientific reasons, such as in attempts to control pests or in efforts to establish new populations in the name of conservation when their original habitat is under threat. Some introductions are recent and precisely documented, others are ancient and of uncertain date. The common pheasant, for example, may well have been brought from the Far East to Greece by Jason and the Argonauts around $1300 \mathrm{BC}$, to be subsequently introduced to the rest of Europe by the Romans.

In many instances the long-term effect of introductions has been deleterious to indigenous birds. Alien species frequently carry diseases to which they have some immunity but to which the indigenous species do not: the effect of avian malaria on many of the endemic species of Hawaii has been devastating. Some species, notably the house sparrow, starlings and pigeons, have become agricultural pests wherever they go, and where introduced species thrive and increase in numbers they generally do so at the expense of native birds. In America, for example, European starlings displace a variety of hole-nesting species from their nest sites. Moving birds from one part of the world to another can lead to hybridization between species that have not had the opportunity to evolve effective reproductive isolation. Thus, the mallard, exported several times from Europe, has hybridized with a number of duck species in Australia and New Zealand.

Competition from introduced species is only one of several factors that have contributed to the demise of the 75 or so species of bird that have become extinct since 1600 . As detailed in Fuller's beautiful book, human greed, vanity or just blind stupidity have been the primary causes of the extermination of birds, for it is clear that, although extinction is the ultimate natural fate of all species, nearly all recently recorded extinctions among birds can be attributed to the direct or indirect effects of human civilization. Colonists from Western Europe have been the worst culprits in this sorry story.

Fuller's book, as it is intended to be, is a worthy successor to Walter Rothschild's classic Extinct Birds, published in 1907. The text is the product of an impressive exercise in scholarship; the author has scoured obscure references, primarily to eye-witness accounts by travellers and explorers, and scrupulously avoids speculation or unsupported inference. Wherever possible, each species is illustrated by a colour painting executed by someone who had actually seen the bird in question. The reproductions are excellent and those by such notable artists as Audubon, Keulemans and Lear, although familiar to most ornithologists, add enormously to the attractiveness and scientific value of the book. The book is arranged taxonomically and the length of each entry reflects the extent of our knowledge of each bird.

Although they deal with very different aspects of ornithology, these two buoks complement one another and have much in common. Both are superbly produced and the respective publishers are to be congratulated on doing justice to the labours of their authors. There is, however, one respect in which both books are of limited value. Although each is meticulously researched and comprehensive in its coverage of the material available, neither author provides a real synthesis of his subject matter. Lever's introduction gives a brief overview of the phenomenon of naturalization, its causes and its consequences, but does not set the phenomenon in the more general context of how the birds of the world are faring at the present time. The format of Fuller's book provides no space for an appraisal of the ultimate reasons why birds become extinct, or of the conservation measures that can be, and in some cases are being taken to prevent further extinctions.

Both books are essentially works of reference and, as such, will be invaluable for future authors who do wish to attempt a more thoughtful and analytical study of the factors which, in a rapidly changing world, cause some birds to flourish while many more decline. They present two sides of a single coin; as we human beings set about the destruction of our habitat, we eliminate rare, exotic and specialized birds while creating openings for a much smaller number of generalist, opportunistic species. The resulting homogeneity in the world's avifauna is a heavy price to pay for the reduction in diversity that we have brought about.

Tim Halliday is Reader in Biology at The Open University, Walton Hall, Milton Keynes $M K 7$ $6 A A, U K$, and author of Vanishing Birds, Their Natural History and Conservation (Sidgwick \& Jackson, 1978).

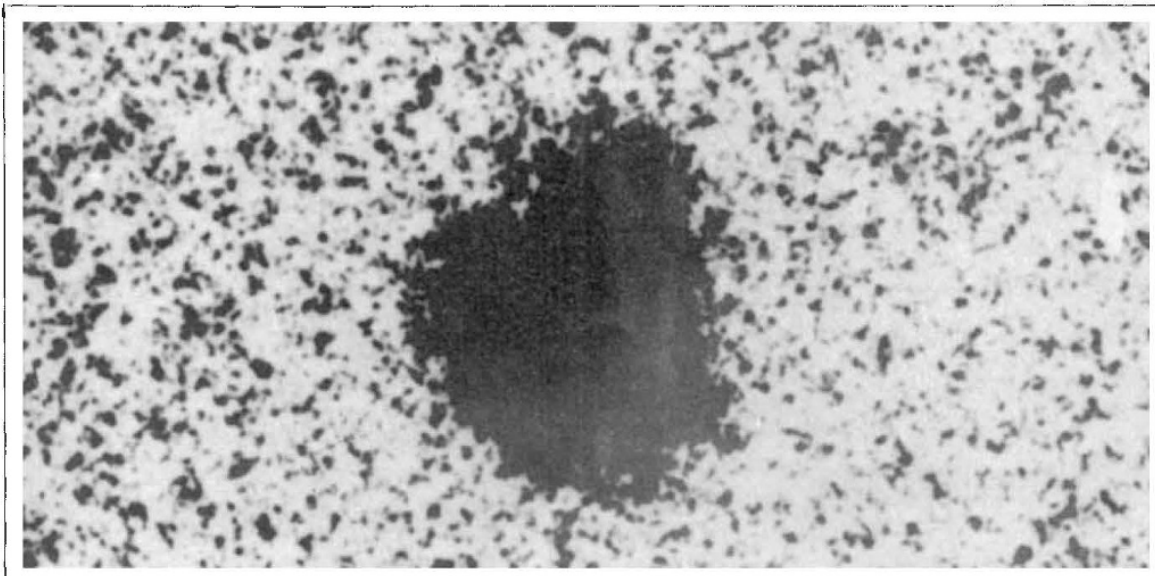

Mis-shapen identity - a mysterious bump first observed in 1978 on photographs of Pluto (here seen on the upper edge), which moves systematically round the planet and which turned out to be a satellite, Charon. The picture is taken from The Universe and Life by G. S. Kutter, which follows the evolution of matter from the big bang to Homo sapiens, with equal emphasis on both physical and biological evolution. Published by Jones \& Bartlett, Boston, the book costs $\$ 40.00$. 